\title{
Quantification of Contralateral Differences of the Scaphoid: A Comparison of Bone Geometry in Three Dimensions
}

\author{
Claudio Letta, ${ }^{1}$ Andreas Schweizer, ${ }^{2}$ and Philipp Fürnstahl ${ }^{3}$ \\ ${ }^{1}$ Department of Surgery, Spital Flawil, Kantonsspital St. Gallen, Krankenhausstrasse 23, 9230 Flawil, Switzerland \\ ${ }^{2}$ Department of Orthopaedic Surgery, University Hospital Balgrist, University of Zurich, Forchstrasse 340, 8008 Zurich, Switzerland \\ ${ }^{3}$ Computer Assisted Research \& Development Group, University Hospital Balgrist, University of Zurich, Forchstrasse 340, \\ 8008 Zurich, Switzerland
}

Correspondence should be addressed to Philipp Fürnstahl; philipp.fuernstahl@card.balgrist.ch

Received 18 November 2013; Accepted 19 December 2013; Published 11 February 2014

Academic Editor: Feng C. Zhou

Copyright (C) 2014 Claudio Letta et al. This is an open access article distributed under the Creative Commons Attribution License, which permits unrestricted use, distribution, and reproduction in any medium, provided the original work is properly cited.

\begin{abstract}
The purpose of this study was to accurately quantify contralateral differences of the scaphoid in three-dimensional space to evaluate the feasibility of using the healthy contralateral bone as a reconstruction template in the preoperative planning of complex malor nonunions. Three-dimensional surface models of the left and right scaphoids were reconstructed from computed tomography images and compared in 26 individuals. Left-right differences were quantified with respect to volume, surface area, length, and surface-to-surface deviation. The average left-right differences in volume, surface area, and length were $95.4 \mathrm{~mm}^{3}\left(\mathrm{SD} 66.2 \mathrm{~mm}^{3}\right)$, $32.7 \mathrm{~mm}^{2}$ (SD $22.9 \mathrm{~mm}^{32}$ ), and $0.28 \mathrm{~mm}$ (SD $\left.0.4 \mathrm{~mm}\right)$, respectively. The average surface-to-surface deviation between the sides was $0.26 \mathrm{~mm}$ (SD $0.2 \mathrm{~mm}$ ). High statistical correlation (Pearson) between the left and the right side was found in all evaluated measures.
\end{abstract}

\section{Introduction}

Scaphoid injury is the most common pathology of the carpal bones [1]. The reported incidence of nonunion after conservative treatment has been more than 12\%; particularly, young men have the highest incident rate $[1,2]$. Most common reasons for scaphoid nonunion are inadequate immobilization or displaced fragments [3]. An established nonunion [4-8] or malunion [9-13] after fracture can lead to pain, loss of function, and osteoarthritis. The preferred treatment option is surgical reduction with internal fixation due to its excellent fracture union rate of more than 95\% $[14,15]$. The aim of treatment should be bone healing with restoration of the scaphoid shape. However, the surgical procedure is challenging [3].

As a consequence, several authors emphasized the importance of preoperative planning [16], since the accuracy of the reduction is primarily dependent on the preoperative quantification $[17,18]$. For the surgical correction of complex mal- or nonunions, the surgeon can use the opposite healthy bone as a guideline $[11,16,18,19]$. Moreover, recently developed computer methods for the 3D preoperative planning of surgical reconstruction do also use the contralateral bone as a gold standard $[18,20]$. For this reasons, the quantitative knowledge of contralateral differences in 3D may help to support the surgeon in the clinical problem. However, leftright variability was rarely evaluated and the exact knowledge about 3D differences is still limited [21].

This study aims at the exact quantification of contralateral differences of the scaphoid bone geometry using computer algorithms. The developed measurement techniques can be applied to $3 \mathrm{D}$ surface models in an automatic fashion to avoid inaccuracies due to manual measurements. Additional emphasis was put on quantifying surface-to-surface deviation between the sides, which is crucial for preoperative planning approaches based on the contralateral bone [18].

\section{Materials and Methods}

Between August 2009 and April 2012, bilateral computed tomography (CT) images had been acquired in 26 patients, who were treated with computer-assisted distal radius osteotomies. Based on these data, we analysed 52 healthy 
scaphoids (26 pairs) with respect to geometrical differences. Approval from the responsible ethics committee and informed patient consent was obtained for analysing this data in a retrospective way. The male-to-female ratio was 15 to 11 and the mean age of the patients was 32 years (SD 15.2 years, range 13-71 years). There was no evidence of scaphoid deformity due to previous trauma.

The image data was acquired using a Philips Brilliance 40 CT device ( $120 \mathrm{kV}$, Philips, Best, The Netherlands) with an axial resolution of $1.0 \mathrm{~mm}$. For preprocessing, the DICOM files were imported into commercially available image processing software (Mimics, Materialise, Leuven, Belgium). The segmentation of the cortical bone layer was performed by applying manual thresholding, followed by region growing in order to separate the scaphoid from surrounding bones. In the last step, a 3D polygonal surface model of the outer bone contour was generated by applying the Marching Cubes algorithm [22].

Different measures were applied to the 3D models of the left and right scaphoids of each subject. Quantification of the geometry, based on orientation-independent features such as volume, surface area, and length, was performed to allow comparison with historical data. Additionally, the surfaceto-surface deviation between the left and the right side was measured.

Methods for precisely computing the surface area and the volume of a 3D model are well known and straightforward. The surface area of the left (right) scaphoid was computed by summing up the area of each polygon (i.e., triangle) of the $3 \mathrm{D}$ model as described in [23].

Before calculating the volume of the surface model, it has to be described as a solid object. To this end, each triangle of the model was converted to an elementary tetrahedron, formed by the three vertices of the triangle and the origin of the coordinate system [23]. The volume of the model was finally determined by summing up the signed volumes of the elementary tetrahedra.

The scaphoid length was quantified using a 3D method not relying on manual measurements. Basically, the length can be determined by measuring the distance between the most proximal and most distal points on the scaphoid poles $[24,25]$. In $3 \mathrm{D}$, we propose to use the concept of the oriented minimum bounding box (OBB) as described in [26]. The OBB encloses all points while its length axis points in direction of the largest possible variance of the data. Therefore, the length (i.e., the largest dimension) of the OBB was used to describe scaphoid length.

In order to determine contralateral differences in surface, the left and right scaphoids were superimposed. To this end, the right scaphoid was mirrored and coarsely aligned to the contralateral bone. Thereafter, the iterative closest point (ICP) surface registration algorithm [27] was applied for accurate and automatic alignment, minimizing the pointto-point distances between the models in a least square sense. This technique was previously used in studies for quantifying scaphoid nonunion [18] as well as for comparing side-to-side differences of the tibia [28]. After registration, the surface-to-surface deviation was measured by comparing the distances between the outer contours of the models on a per-point basis. The mean surface-to-surface deviation (i.e., the root mean squared error RMSE) was defined as the average distance from the points of one model to the closest point on the other model.

Statistical analysis of the data was carried out using the software R (R Foundation, Vienna, Austria).

\section{Results and Discussion}

3.1. Results. The results with respect to the proposed measures are given in Tables 1 and 2. The average left-right differences in volume, surface area, and scaphoid length among all subjects were $95 \mathrm{~mm}^{3}$ (SD $66 \mathrm{~mm}^{3}$, range: $4.8-235 \mathrm{~mm}^{3}$ ), $32 \mathrm{~mm}^{2}$ (SD $22 \mathrm{~mm}^{2}$, range: $0.7-84 \mathrm{~mm}^{2}$ ), and $0.5 \mathrm{~mm}$ (SD $0.4 \mathrm{~mm}$, range: $0-1.4 \mathrm{~mm}$ ), respectively. For these parameters, no significant side-to-side difference (Welch two sample $t$ test, $P \gg 0.05$ ) between men (average difference in volume $101 \mathrm{~mm}^{3}$, area $34 \mathrm{~mm}^{2}$, and length $0.5 \mathrm{~mm}$ ) and women (average difference in volume $87 \mathrm{~mm}^{3}$, area $30 \mathrm{~mm}^{2}$, and length $0.6 \mathrm{~mm}$ ) could be observed. Contrary, the contralateral surface-to-surface deviation was significantly different (Welch Two Sample $t$-test, $P<0.05$ ) between those groups with respect to both, the average and maximum left-right surface error. In men, the surface error was significantly higher (average $0.28 \mathrm{~mm}$, SD $0.05 \mathrm{~mm}$ ) as in women (average $0.22 \mathrm{~mm}$, SD $0.05 \mathrm{~mm}$ ). Figures 1 and 2 visualize the scaphoids having the largest (up to $1.9 \mathrm{~mm}$ ) and smallest (up to $0.73 \mathrm{~mm}$ ) surface deviations. On average, the surface error was $0.26 \mathrm{~mm}$ (SD $0.2 \mathrm{~mm}$ ) in the 26 subjects. The correlation between the left and the right sides was very high (Pearson, $P<0.01,2$-tailed), being 0.99 for surface and volume and 0.98 for the other measures.

In addition to the contralateral evaluation, the data allowed us to compare the variability of the scaphoids between subjects. The average volume of the left and right scaphoid among all subjects was $2500.0 \mathrm{~mm}^{3}$ (SD $962.2 \mathrm{~mm}^{3}$, range: $748-4931 \mathrm{~mm}^{3}$ ) and $2518.6 \mathrm{~mm}^{3}$ (SD $987.4 \mathrm{~mm}^{3}$, range: $877-4986 \mathrm{~mm}^{3}$ ), respectively. The average surface area was $1097 \mathrm{~mm}^{2}$ (SD $286 \mathrm{~mm}^{2}$, range: $459-1728 \mathrm{~mm}^{2}$ ) for the left side and $1099 \mathrm{~mm}^{2}$ (SD $287 \mathrm{~mm}^{2}$, range: $513-1722 \mathrm{~mm}^{2}$ ) for the right side. On average, the length of the left and right scaphoids was $26.75 \mathrm{~mm}$ (SD $3.7 \mathrm{~mm}$, range: $16-33.9 \mathrm{~mm}$ ) and $26.85 \mathrm{~mm}$ (SD $3.9 \mathrm{~mm}$, range: $16.2-34 \mathrm{~mm}$ ).

The size of the scaphoid between genders differed significantly (Welch two sample $t$-test, $P<0.05$ ) in volume, surface area, and length, considering only adult subjects. Male had a larger scaphoid volume (40\% larger on average), surface area (20\% larger on average), and length (10\% larger on average) than female.

3.2. Discussion. Compson and colleagues [29] were one of the first who mentioned the importance of considering the 3D shape of the scaphoid for performing surgical treatment. They concluded that $2 \mathrm{D}$ radiological images were insufficient to describe the complex shape of the scaphoid. Therefore, 3D preoperative analysis is essential for appropriate treatment of scaphoid nonunion $[17,30]$ and the use of $3 \mathrm{D}$ methods for 
TABLE 1: Quantitative evaluation of the 3D scaphoid geometry.

\begin{tabular}{|c|c|c|c|c|c|c|}
\hline & Volume L $\left(\mathrm{mm}^{3}\right)$ & Volume $\mathrm{R}\left(\mathrm{mm}^{3}\right)$ & Area L $\left(\mathrm{mm}^{2}\right)$ & Area $\mathrm{R}\left(\mathrm{mm}^{2}\right)$ & Length L (mm) & Length R (mm) \\
\hline Woman & $\begin{array}{c}2021 \text { (SD 602) } \\
1146-3131\end{array}$ & $\begin{array}{c}2041 \text { (SD 645) } \\
1133-3364\end{array}$ & $\begin{array}{c}951 \text { (SD 193), } \\
654-1307\end{array}$ & $\begin{array}{c}960 \text { (SD 205), } \\
658-1374\end{array}$ & $\begin{array}{c}25 \text { (SD 2.3) } \\
21.3-29.4\end{array}$ & $\begin{array}{c}25.2(\text { SD 2.8) } \\
21.2-30.8\end{array}$ \\
\hline Men & $\begin{array}{c}2851 \text { (SD 1040), } \\
749-4932\end{array}$ & $\begin{array}{c}2869 \text { (SD 1064), } \\
878-4986\end{array}$ & $\begin{array}{c}1205 \text { (SD 11) } \\
460-1729\end{array}$ & $\begin{array}{c}1201 \text { (SD 312) } \\
514-1722\end{array}$ & $\begin{array}{c}28 \text { (SD 4.5), } \\
16-33.9\end{array}$ & $\begin{array}{c}28 \text { (SD 4.4) } \\
16.2-34\end{array}$ \\
\hline Both & $\begin{array}{c}2500(\text { SD 262) } \\
749-4932\end{array}$ & $\begin{array}{c}2519 \text { (SD 987) } \\
878-4986\end{array}$ & $\begin{array}{c}1097 \text { (SD 292) } \\
460-1729\end{array}$ & $\begin{array}{c}1099 \text { (SD 293) } \\
514-1722\end{array}$ & $\begin{array}{c}26.8 \text { (SD 4) } \\
16-33.9\end{array}$ & $\begin{array}{c}26.9(\mathrm{SD} 4) \\
16.2-34\end{array}$ \\
\hline
\end{tabular}

Average, standard deviation (SD), and range in volume, surface area, and maximal length of the left (L) and right (R) scaphoids are given for woman (first row), men (second row), and for all subjects (third row). SD denotes the standard deviation.

TABLE 2: Contralateral differences of the 3D scaphoid geometry.

\begin{tabular}{|c|c|c|c|c|}
\hline & Volume L, R diff $\left(\mathrm{mm}^{3}\right)$ & Area L, R diff $\left(\mathrm{mm}^{2}\right)$ & Length L, R diff $\left(\mathrm{mm}^{2}\right)$ & $\begin{array}{l}\text { Average surface deviation } \\
(\mathrm{mm})\end{array}$ \\
\hline Woman & $\begin{array}{c}87.4(\mathrm{SD} 74.7) \\
10.2-235.1 \\
\end{array}$ & $\begin{array}{c}30.2(\mathrm{SD} 21.9) \\
1.6-67.2 \\
\end{array}$ & $\begin{array}{c}0.6(\mathrm{SD} 0.5) \\
0-1.4\end{array}$ & $\begin{array}{c}0.22(\mathrm{SD} \mathrm{0.04)} \\
0-1.84\end{array}$ \\
\hline Men & $\begin{array}{c}101.1(\mathrm{SD} 61.4) \\
4.8-234.1 \\
\end{array}$ & $\begin{array}{c}34.5(\mathrm{SD} 24.3) \\
0.7-85 \\
\end{array}$ & $\begin{array}{c}0.5(\mathrm{SD} 0.4) \\
0-1.4\end{array}$ & $\begin{array}{c}0.28 \text { (SD 0.06) } \\
0-1.98\end{array}$ \\
\hline Both & $\begin{array}{c}95.3 \text { (SD 66.2) } \\
4.8-235.1\end{array}$ & $\begin{array}{c}32.7 \text { (SD 22.9), } \\
0.7-85\end{array}$ & $\begin{array}{c}0.2(\mathrm{SD} 0.4) \\
0-1.4\end{array}$ & $\begin{array}{c}0.26 \text { (SD 0.2) } \\
0-1.98\end{array}$ \\
\hline
\end{tabular}

Average contralateral difference, standard deviation (SD), and range in volume, surface area, and maximal length between the left (L) and right (R) scaphoids are given for woman (first row), men (second row), and for all subjects (third row).

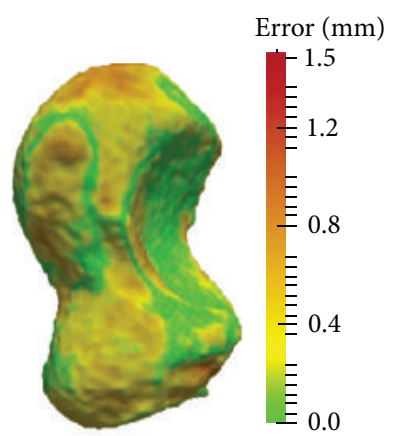

(a)

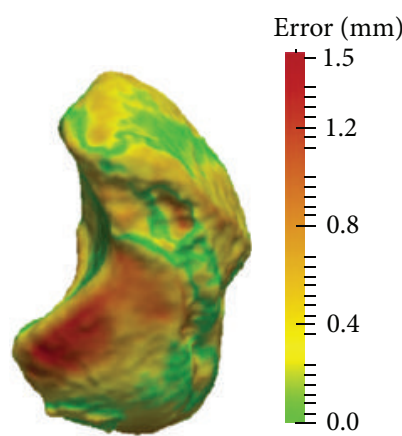

(b)

FIGURE 1: Scaphoid with the largest left-right surface distance error in all subjects. Left and right scaphoids are given.

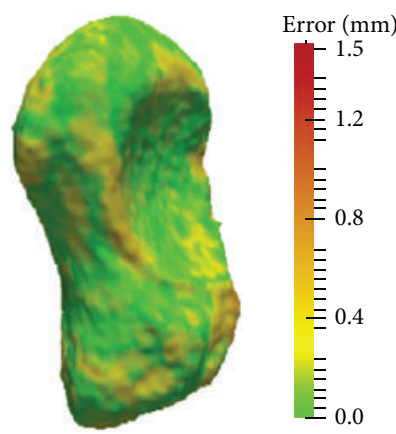

(a)

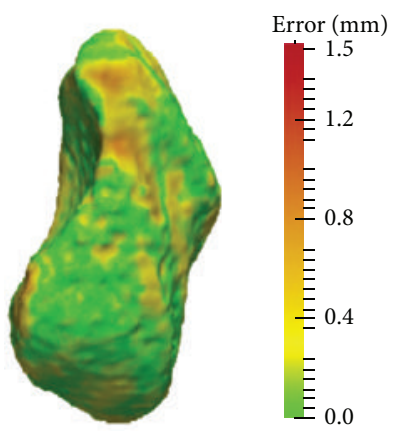

(b)

FIGURE 2: Scaphoid with the smallest left-right surface distance error in all subjects. Left and right scaphoids are given. 
measuring surface deviation may help to identify important contralateral differences.

Several studies analysed the anthropometry, morphology, and geometry of carpal scaphoids [17, 24, 25, 29-32] with the purpose to improve treatment of scaphoid fractures $[1,2,4,6$, $14,15]$ and nonunions [5, 7-10, 12, 17, 18]. Consistent with our results, a significant difference in size and length between the genders was demonstrated [24, 25, 30, 32].

The dimension of the scaphoid, particularly its length, was determined manually in CT [25,30], MRI [32], and cadavers [24]. The scaphoid length in our study (men, average $27.5 \mathrm{~mm}$ and SD $4.4 \mathrm{~mm}$; women, average $25 \mathrm{~mm}$ and SD $2.5 \mathrm{~mm}$ ) was similar to the study of Pichler et al. [25] (men, average $27.8 \mathrm{~mm}$ and SD $1.6 \mathrm{~mm}$; women, average $24.5 \mathrm{~mm}$ and SD $1.6 \mathrm{~mm}$ ), smaller than in the studies of Heinzelmann et al. [24] (men, average $31.3 \mathrm{~mm}$ and SD $2.1 \mathrm{~mm}$; women, average $27.3 \mathrm{~mm}$ and SD $1.7 \mathrm{~mm}$ ) and Patterson et al. [30] (men, average $29.2 \mathrm{~mm}$ and SD $3.75 \mathrm{~mm}$; women, average $25.5 \mathrm{~mm}$ and SD $2.3 \mathrm{~mm}$ ), and larger than in the evaluation of Smith [32] (men, average $26 \mathrm{~mm}$ and SD $1.9 \mathrm{~mm}$; women, average $22.5 \mathrm{~mm}$ and SD $1.4 \mathrm{~mm}$ ). Pichler et al. also used a 3D surface model as the geometric representation which may be an explanation for the similar results.

Patterson et al. estimated the surface area and volume by approximating the shape with a set of cylinders, manually created on the slices of the CT image. Their measured volume (men, average $2524 \mathrm{~mm}^{3}$, SD $846 \mathrm{~mm}^{3}$; woman, average $1675 \mathrm{~mm}^{3}, \mathrm{SD} 482 \mathrm{~mm}^{3}$ ) and surface area (men, average $1235 \mathrm{~mm}^{2}$, SD $277 \mathrm{~mm}^{2}$; woman, average $920 \mathrm{~mm}^{2}$, SD $178 \mathrm{~mm}^{2}$ ) correlate well with the volume (men, average $2879 \mathrm{~mm}^{3}$, SD $1116 \mathrm{~mm}^{3}$; woman, average $2042 \mathrm{~mm}^{3}$, SD $638 \mathrm{~mm}^{3}$ ) and surface area (men, average $1141 \mathrm{~mm}^{2}$, SD $324 \mathrm{~mm}^{2}$; woman, average $954 \mathrm{~mm}^{2}$, SD $204 \mathrm{~mm}^{2}$ ) of our study. Pichler et al. developed a different method to measure the scaphoid volume. The volume was approximated by a polyhedron consisting of 16 points which were selected according to anatomical landmarks. However, their results (men, average $4058 \mathrm{~mm}^{3}, \mathrm{SD} 741 \mathrm{~mm}^{3}$; woman, average $2846 \mathrm{~mm}^{3}$, SD $618 \mathrm{~mm}^{3}$ ) differed considerably from other findings.

Only some of these studies [21, 30, 32] performed a comparison between the left and the right scaphoids. Patterson et al. described a CT-based analysis of 35 adult wrists obtained from 21 cadavers and 14 patients. They did not observe any significant difference between the left and right scaphoids with respect to wrist dimension. Smith [32] validated leftright symmetry based on three biometric measurements (i.e., scaphoid length, proximal pole height, and sagittal interscaphoid angle), identified in ultrathin $(0.7 \mathrm{~mm}$ slice thickness) MRI-scans of 30 healthy subjects. The contralateral differences of these measurements were minimal (below $0.8 \mathrm{~mm}$ and $3.3^{\circ}$ ), showing a left-right correlation coefficient of 0.92 to 0.98 . Heinzelmann et al. studied 30 pairs of cadaveric scaphoids. They did not found any considerable side-toside difference between the left and the right side with respect to proximal pole, distal pole, waist, or length measurements. In a cadaveric study of Ceri et al. [21], 200 scaphoid bones were used to assess 11 morphometric parameters for left-right comparison. The contralateral length difference was $0.1 \mathrm{~mm}$ on average. In contrast to the other studies, significant sideto-side differences were found in 4 morphometric features (i.e., circumference of the waist, base of the tubercle, width of the main sulcus, and the secondary height of the tubercle). These results roughly agree with our study, where the average maximum surface-to-surface deviation was $1.23 \mathrm{~mm}$. However, the differences reported by Ceri et al. were considerably smaller than their intra- and interobserver variability of $1.3 \mathrm{~mm}$ and $1.8 \mathrm{~mm}$, respectively.

The discussion of previous work showed that very few studies quantified contralateral differences of the scaphoid, measuring only basic parameters. The evaluations relied on manual measurements, which may bias small left-to-right differences due to observer variability. Contrary, computerbased algorithms were applied to different anatomy for measuring surface differences in a more comprehensive way [28]. Similar methods were also used for 3D preoperative planning of the scaphoid [17, 18] and forearm bones [33]. Therefore, we used surface registration algorithms to evaluate surfaceto-surface deviation of the scaphoid, which is strength of our study. Another advantage of our approach is that the proposed methods work in an automated fashion. Moreover, we used algorithms for surface area and volume computation [23], which can be accurately applied to surface models, instead of approximating these measurements $[25,30]$. Limitations of the study are the relatively small sample size and the fact that only the cortical bone layer was examined without consideration of potential differences due to cartilage.

\section{Conclusions}

The scaphoid has a twisted and bean-formed shape which makes the analysis of complex mal- and nonunions based on conventional radiographs difficult. State-of-the-art computer-assisted surgical planning approaches rely on the contralateral scaphoid as a $3 \mathrm{D}$ reconstruction template. The goal of this study was to precisely quantify potential left-right differences with $3 \mathrm{D}$ techniques without estimating measurements. The evaluation of surface-tosurface differences revealed that regions of the scaphoid may differ up to $1.9 \mathrm{~mm}$. This fact must be taken into account if the contralateral scaphoid should be used in surgical planning. Furthermore, the surface-to-surface deviation between men was significantly higher than in women. As in previous studies, high correlation between the left and right scaphoids with respect to volume, surface area, and length was observed.

\section{Disclosure}

This research received no specific grant from any funding agency in the public, commercial, or not-for-profit sectors.

\section{Conflict of Interests}

The authors declare that there is no conflict of interests regarding the publication of this paper. 


\section{Acknowledgment}

Retrospective cohort study, Level 3.

\section{References}

[1] J. J. Dias, I. J. Brenkel, and D. B. L. Finlay, "Patterns of union in fractures of the waist of the scaphoid," Journal of Bone and Joint Surgery B, vol. 71, no. 2, pp. 307-310, 1989.

[2] I. J. Leslie and R. A. Dickson, "The fractured carpal scaphoid. Natural history and factors influencing outcome," Journal of Bone and Joint Surgery B, vol. 63, no. 2, pp. 225-230, 1981.

[3] F. Schuind, P. Haentjens, F. Van Innis, C. Vander Maren, M. Garcia-Elias, and G. Sennwald, "Prognostic factors in the treatment of carpal scaphoid nonunions," Journal of Hand Surgery, vol. 24, no. 4, pp. 761-776, 1999.

[4] H. Duppe, O. Johnell, G. Lundborg, M. Karlsson, and I. Redlund-Johnell, "Long-term results of fracture of the scaphoid. A follow-up study of more than thirty years," Journal of Bone and Joint Surgery A, vol. 76, no. 2, pp. 249-252, 1994.

[5] L. Kerluke and S. J. McCabe, "Nonunion of the scaphoid: a critical analysis of recent natural history studies," Journal of Hand Surgery, vol. 18, no. 1, pp. 1-3, 1993.

[6] S. H. Kozin, "Incidence, mechanism, and natural history of scaphoid fractures," Hand Clinics, vol. 17, no. 4, pp. 515-524, 2001.

[7] G. Lindstrom and A. Nystrom, "Natural history of scaphoid non-union, with special refrence to "asymptomatic" cases," Journal of Hand Surgery, vol. 17, no. 6, pp. 697-700, 1992.

[8] G. R. Mack, M. J. Bosse, R. H. Gelberman, and E. Yu, “The natural history of scaphoid non-union," Journal of Bone and Joint Surgery A, vol. 66, no. 4, pp. 504-509, 1984.

[9] P. C. Amadio, T. H. Berquist, D. K. Smith, D. M. Illstrup, W. P. Cooney III, and R. L. Linscheid, "Scaphoid malunion," Journal of Hand Surgery, vol. 14, no. 4, pp. 679-687, 1989.

[10] R. C. Burgess, "The effect of a simulated scaphoid malunion on wrist motion," Journal of Hand Surgery, vol. 12, no. 5, pp. 774776, 1987.

[11] J. L. Condamine, M. Lebourg, and G. Raimbeau, "Analysis of twenty-eight recurrent pseudarthroses of the carpal navicular after the Matti-Russe operation," Annales de Chirurgie de la Main, vol. 5, no. 4, pp. 269-280, 1986.

[12] D. L. Fernandez, C. J. Martin, and J. G. Del Pino, "Scaphoid malunion: the significance of rotational malalignment," Journal of Hand Surgery, vol. 23, no. 6, pp. 771-775, 1998.

[13] P. Saffar, "Scaphoid malunion," Chirurgie de la Main, vol. 27, no. 2-3, pp. 65-75, 2008.

[14] T. J. Herbert and W. E. Fisher, "Management of the fractured scaphoid using a new bone screw," Journal of Bone and Joint Surgery B, vol. 66, no. 1, pp. 114-123, 1984.

[15] J. J. Dias, C. J. Wildin, B. Bhowal, and J. R. Thompson, "Should acute scaphoid fractures be fixed? A randomized controlled trial," Journal of Bone and Joint Surgery A, vol. 87, no. 10, pp. 2160-2168, 2005.

[16] D. L. Fernandez, "A technique for anterior wedge-shaped grafts for scaphoid nonunions with carpal instability," Journal of Hand Surgery, vol. 9, no. 5, pp. 733-737, 1984.

[17] K. Oka, H. Moritomo, T. Murase, A. Goto, K. Sugamoto, and H. Yoshikawa, "Patterns of carpal deformity in scaphoid nonunion: a 3-dimensional and quantitative analysis," Journal of Hand Surgery, vol. 30, no. 6, pp. 1136-1144, 2005.
[18] A. Schweizer, P. Fürnstahl, and L. Nagy, “Three-dimensional computed tomographic analysis of 11 scaphoid waist nonunions," Journal of Hand Surgery, vol. 37, no. 6, pp. 1151-1158, 2012.

[19] W. P. Cooney, R. L. Linscheid, J. H. Dobyns, and M. B. Wood, "Scaphoid nonunion: role of anterior interpositional bone grafts," Journal of Hand Surgery, vol. 13, no. 5, pp. 635-650, 1988.

[20] T. Murase, H. Moritomo, A. Goto, K. Sugamoto, and H. Yoshikawa, "Does three-dimensional computer simulation improve results of scaphoid nonunion surgery?" Clinical Orthopaedics and Related Research, no. 434, pp. 143-150, 2005.

[21] N. Ceri, E. Korman, I. Gunal, and S. Tetik, "The morphological and morphometric features of the scaphoid," Journal of Hand Surgery, vol. 29, no. 4, pp. 393-398, 2004.

[22] W. E. Lorensen and H. E. Cline, "Marching cubes: a high resolution 3D surface construction algorithm," Computer Graphics, vol. 21, no. 4, pp. 163-169, 1987.

[23] Z. Cha and C. Tsuhan, "Efficient feature extraction for 2D/3D objects in mesh representation," in Proceedings of the International Conference (ICIP '01), 2001.

[24] A. D. Heinzelmann, G. Archer, and R. R. Bindra, "Anthropometry of the human scaphoid," Journal of Hand Surgery, vol. 32, no. 7, pp. 1005-1008, 2007.

[25] W. Pichler, G. Windisch, G. Schaffler, N. Heidari, K. Dorr, and W. Grechenig, "Computer-assisted 3-dimensional anthropometry of the scaphoid," Orthopedics, vol. 33, no. 2, pp. 85-88, 2010.

[26] P. J. Schneider and D. Eberly, Geometric Tools for Computer Graphics, Elsevier Science, 2002.

[27] Y. Chen and G. Medioni, "Object modeling by registration of multiple range images," in Proceedings of the IEEE International Conference on Robotics and Automation, pp. 2724-2729, April 1991.

[28] P. Krishnakanth, B. Schmutz, R. Steck, S. Mishra, M. A. Schütz, and D. R. Epari, "Can the contra-lateral limb be used as a control with respect to analyses of bone remodelling?" Medical Engineering and Physics, vol. 33, no. 8, pp. 987-992, 2011.

[29] J. P. Compson, J. K. Waterman, and F. W. Heatley, "The radiological anatomy of the scaphoid. Part 1: osteology," Journal of Hand Surgery, vol. 19, no. 2, pp. 183-187, 1994.

[30] R. M. Patterson, K. W. Elder, S. F. Viegas, and W. L. Buford, "Carpal bone anatomy measured by computer analysis of threedimensional reconstructions of computed tomography images," Journal of Hand Surgery, vol. 20, no. 6, pp. 923-929, 1995.

[31] M. F. Meek and C. Heras-Palou, "Anthropometry of the human scaphoid," Journal of Hand Surgery, vol. 33, no. 2, p. 285, 2008.

[32] D. K. Smith, "Anatomic features of the carpal scaphoid: validation of biometric measurements and symmetry with threedimensional MR imaging," Radiology, vol. 187, no. 1, pp. 187-191, 1993.

[33] A. Schweizer, P. Fürnstahl, M. Harders, G. Székely, and L. Nagy, "Complex radius shaft malunion: osteotomy with computerassisted planning," Hand, vol. 5, no. 2, pp. 171-178, 2010. 

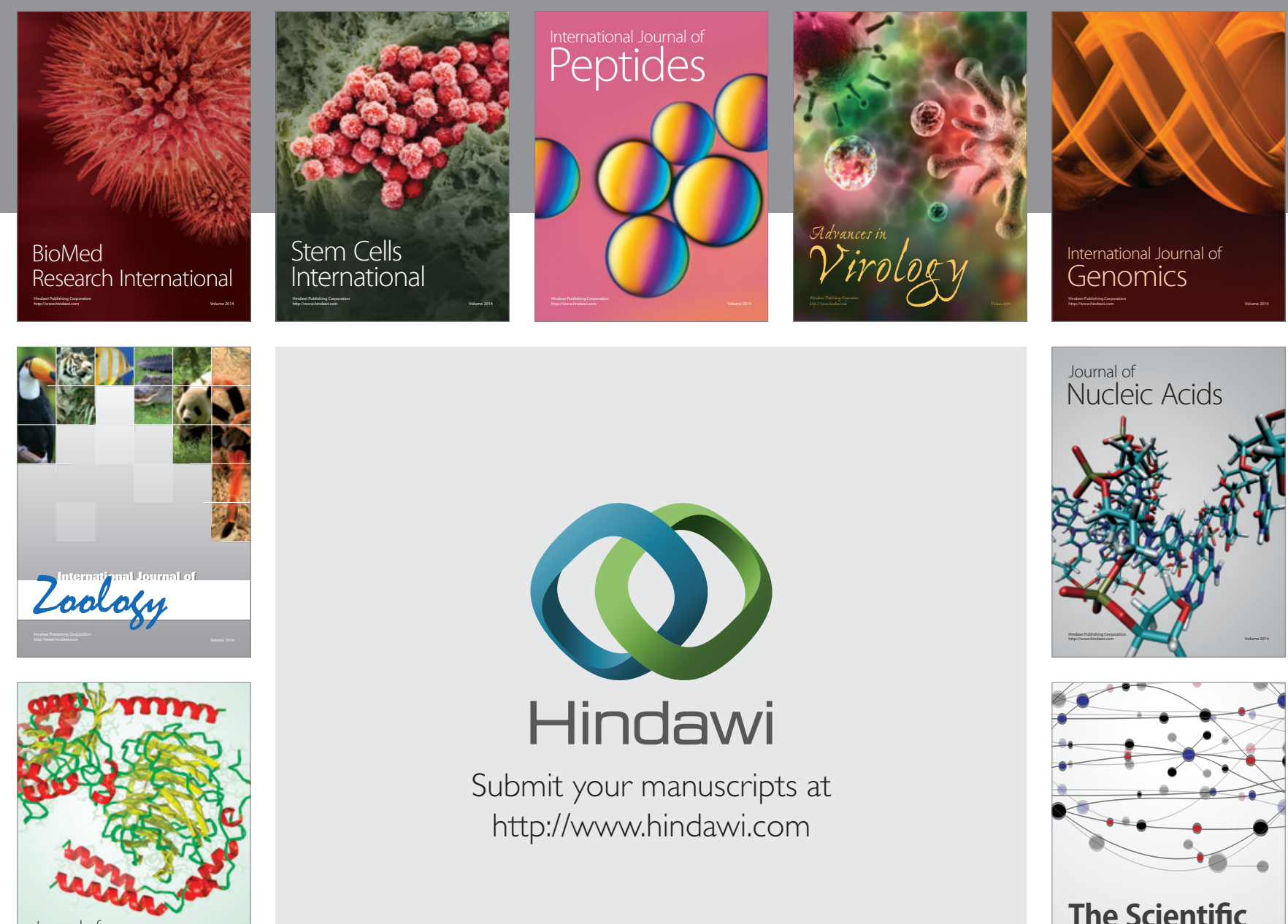

Submit your manuscripts at

http://www.hindawi.com

Journal of
Signal Transduction
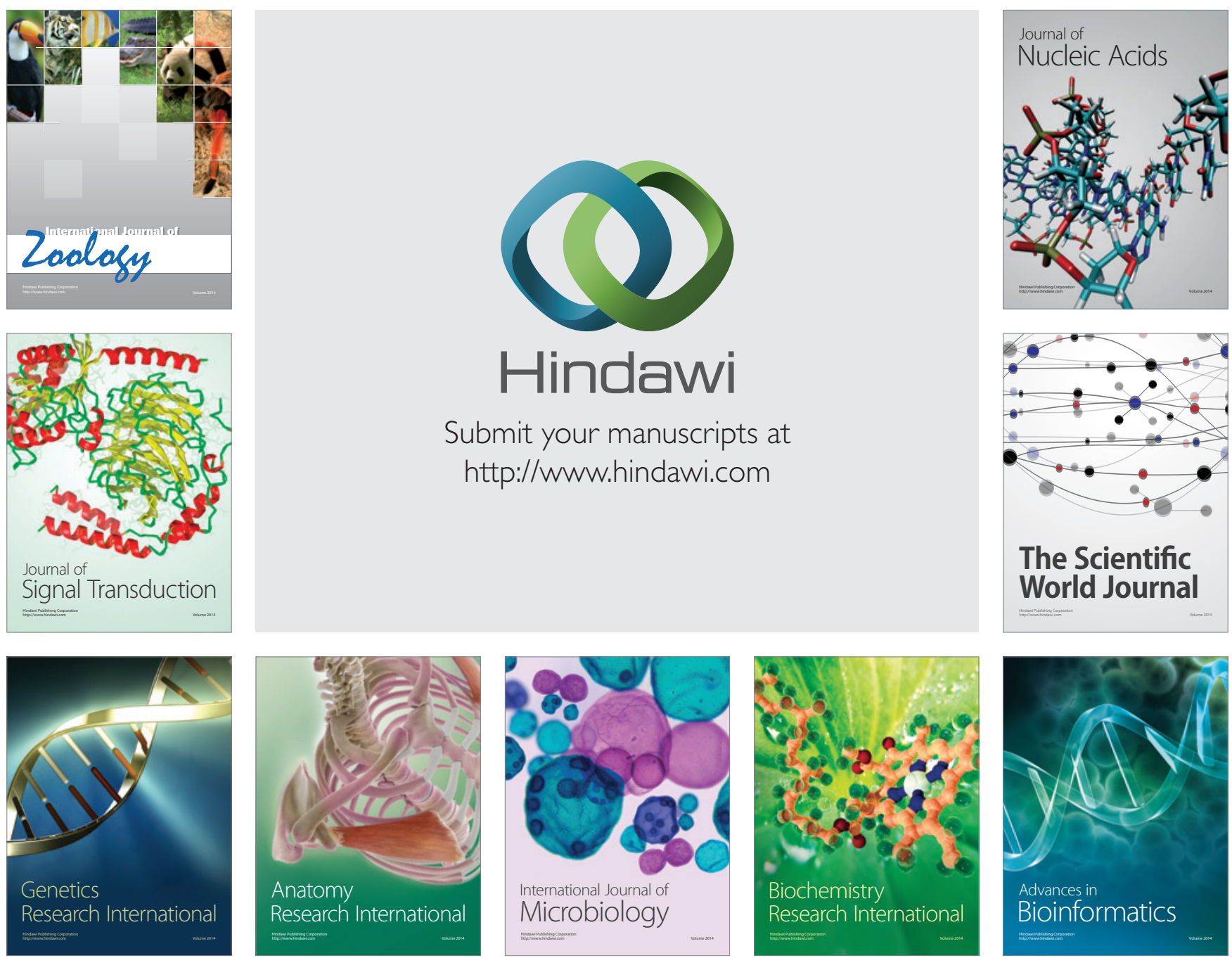

The Scientific World Journal
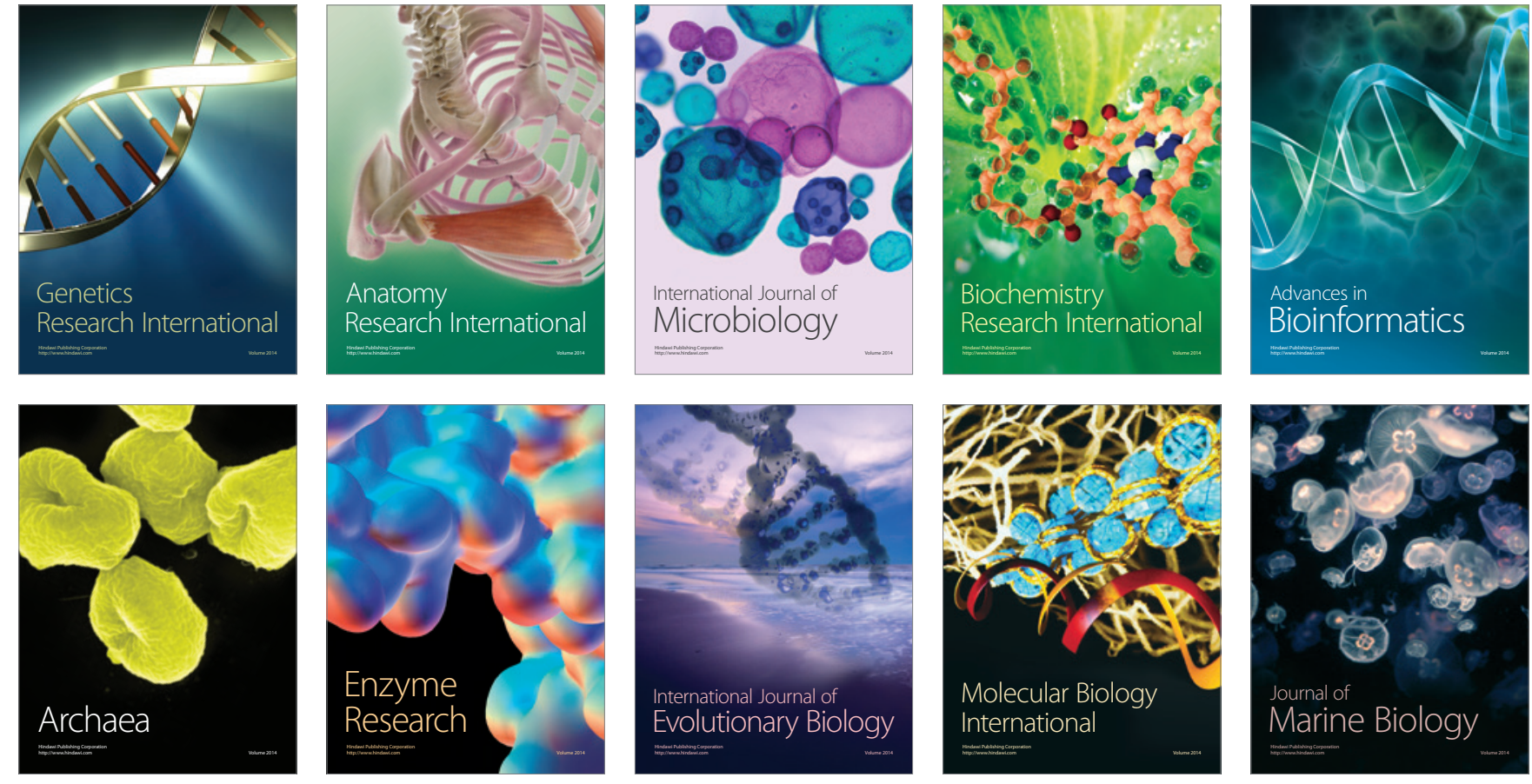